\title{
Pneumothorax ex vacuo in a Patient with Malignant Pleural Effusion After PleurX Catheter Placement
}

\author{
Meera Bhardwaj, MS4 \\ Thomas Jefferson University, meera.bhardwaj@jefferson.edu \\ Loheetha Ragupathi, MD \\ Thomas Jefferson University, Loheetha.ragupathi@jefferson.edu
}

Follow this and additional works at: https://jdc.jefferson.edu/tmf

Part of the Medicine and Health Sciences Commons

Let us know how access to this document benefits you

\section{Recommended Citation}

Bhardwaj, MS4, Meera and Ragupathi, MD, Loheetha (2015) "Pneumothorax ex vacuo in a Patient with Malignant Pleural Effusion After PleurX Catheter Placement," The Medicine Forum: Vol. 16, Article 20. DOI: https://doi.org/10.29046/TMF.016.1.019

Available at: https://jdc.jefferson.edu/tmf/vol16/iss1/20

This Article is brought to you for free and open access by the Jefferson Digital Commons. The Jefferson Digital Commons is a service of Thomas Jefferson University's Center for Teaching and Learning (CTL). The Commons is a showcase for Jefferson books and journals, peer-reviewed scholarly publications, unique historical collections from the University archives, and teaching tools. The Jefferson Digital Commons allows researchers and interested readers anywhere in the world to learn about and keep up to date with Jefferson scholarship. This article has been accepted for inclusion in The Medicine Forum by an authorized administrator of the Jefferson Digital Commons. For more information, please contact: JeffersonDigitalCommons@jefferson.edu. 


\title{
Pneumothorax ex vacuo in a Patient with Malignant Pleural Effusion After PleurX Catheter Placement
}

\author{
Meera Bhardwaj, MS4 and Loheetha Ragupathi, MD
}

\section{INTRODUCTION}

Pneumothorax ex vacuo ("without vaccuum") is a type of pneumothorax that can develop in patients with large pleural effusions. Unlike spontaneous or tension pneumothoraces, pneumothorax ex vacuo does not require chest tube placement. Careful recognition of this type of pneumothorax may save patients and physicians from an unnecessary procedure, and limit patient risk of infection, bleeding and further lung injury.

\section{CASE REPORT}

An 81 year old woman with a history of osteoarthritis, depression, and remote smoking history, presented to her primary care provider complaining of progressive cough, dyspnea, and $30 \mathrm{lb}$ unintentional weight loss. An outpatient chest radiograph revealed total opacification of the right lung. She was admitted to the hospital for further management. Computed tomography showed a large right pleural effusion with partial collapse of the right lung, bilateral pulmonary nodules, and obliteration of the right lower lobe bronchus. A diagnostic thoracentesis showed an exudative effusion, and cytology was consistent with primary lung adenocarcinoma. Bronchoscopy revealed an aerated right upper lobe, and endobronchial biopsy was unrevealing.

Due to worsening hypoxia, a PleurX drainage catheter was placed, and one liter of pleural fluid was removed daily. Lungs were monitored with post-drainage radiographs, and the patient improved clinically. Five days after PleurX placement, however, she was noted to develop right upper lobe atelectasis and a right apical pneumothorax with no tracheal deviation (Figure 1). In the setting of collapsed lung due to sudden atelectasis, this represented pneumothorax ex vacuo. Her management continued unchanged and she was safely discharged to a rehabilitation facility with pneumothorax ex vacuo and PleurX catheter in place.

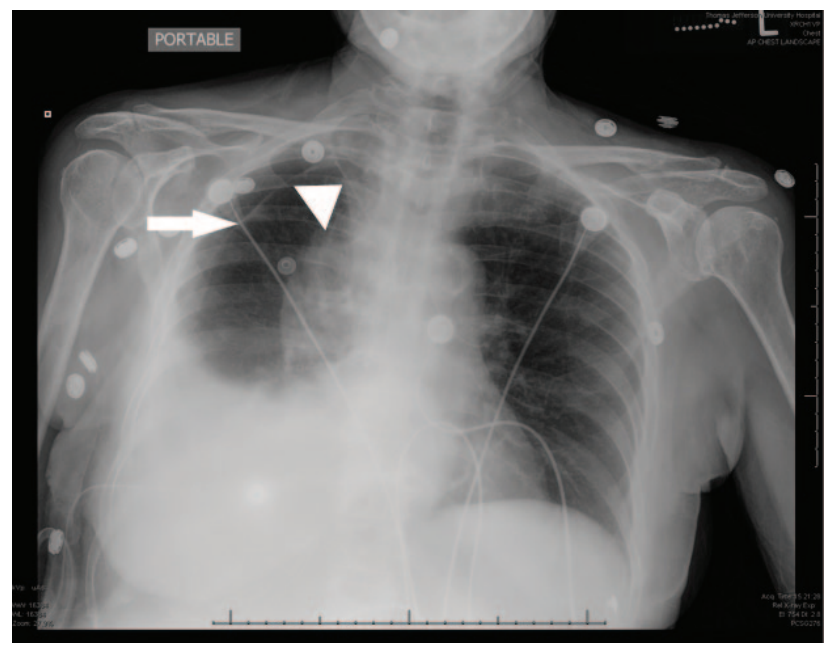

Figure 1. Portable chest radiograph demonstrating right upper lobe atelectasis (white arrow head) with pneumothorax ex vacuo (white arrow), in the setting of right pleural effusion and right-sided PleurX catheter.

Pneumothorax ex vacuo: A pneumothorax ex vacuo was traditionally thought to develop when a mucus plug, foreign body, or extrabronchial mass obstructs a bronchus causing acute lobar collapse. The sudden lobar collapse generates a negative intrapleural pressure that draws gas-mainly nitrogen-from the neighboring tissues and blood into the adjacent pleural space. ${ }^{1}$ More recently, pneumothorax ex vacuo is also thought to develop when a lung is unable to re-expand following drainage of pleural fluid. ${ }^{23}$ The seal between the visceral and parietal pleura remains intact at the sites of the aerated lobes, causing the pneumothorax ex vacuo to surround only the collapsed lobe, distinguishing it from both tension and spontaneous pneumothoraces. ${ }^{1}$ Boland et al. ${ }^{2}$ and Ponrartana et al. ${ }^{3}$ demonstrate that chest tubes are not beneficial for asymptomatic patients with malignant lung parenchymal disease and pneumothorax ex vacuo. Malignant infiltration of the lung tissue leads to poor lung compliance and unresponsiveness to chest tubes. ${ }^{2}$ One hypothesis is that malignant cells create a fibrinous peel limiting re-expansion of the lung, while 
another suggests that chronic atelectasis, interrupted blood flow, and pulmonary edema decrease production of pulmonary surfactant prohibiting lung re-expansion after pleural fluid drainage. ${ }^{3}$ Observation is appropriate and sufficient in asymptomatic patients. ${ }^{2,3}$ If there is concern for trapped lung, Pien et al. found that PleurX catheter placement is an effective treatment. ${ }^{4}$

\section{KEY POINTS:}

Pneumothorax ex vacuo develops in the setting of sudden acute lobar collapse, and persists from an inability of the lung to re-expand. Unlike tension or spontaneous pneumothoraces, it only surrounds the atelectatic lobe and does not surround the lobe(s) that are healthy and aerated. ${ }^{1}$ Unlike spontaneous and tension pneumothoraces, pneumothorax ex vacuo should be observed without chest tube placement in the asymptomatic patient. ${ }^{2,3}$

\section{REFERENCES}

1. Woodring JH, Baker MD, Stark P. Pneumothorax ex vacuo. Chest 1996 Oct;110(4):1102-5.

2. Boland GW, Gazelle GS, Girard MJ, Mueller PR. Asymptomatic hydropneumothorax after therapeutic thoracentesis for malignant pleural effusions. AJR Am J Roentgenol. 1998 Apr; 170 (4):943-6.

3. Ponrartana S, Laberge JM, Kerlan RK, Wilson MW, Gordon RL. Management of patients with ex vacuo pneumothorax after thoracentesis. Acad Radiol. 2005 Aug; 12 (8):980-6.

4. Pien G, Gant MJ, Washam C, Sterman D H. Use of an Implantable Pleural Catheter for Trapped Lung Syndrome in Patients With Malignant Pleural Effusion. Chest. 2001; 119:1641-1646.

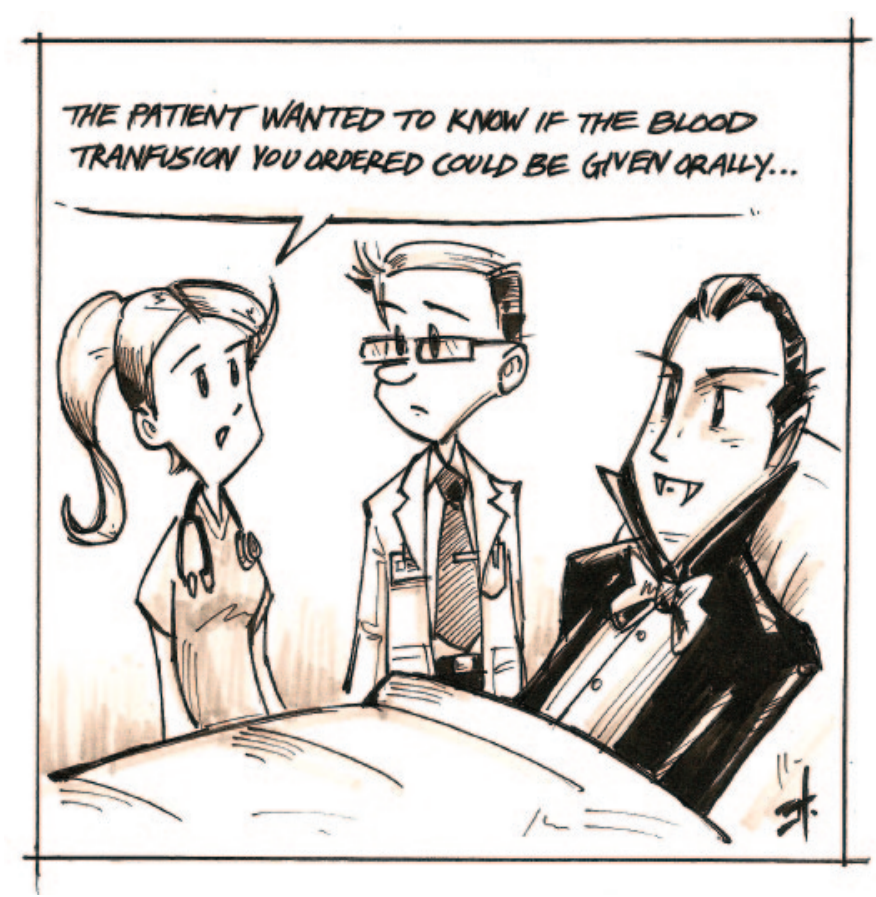

